\title{
Study on Experiment of Concrete Strength with Numerical Simulation
}

\author{
Xiao Sun ${ }^{1,2, a}$ \\ ${ }^{1}$ Nanchang Institute of Technology, Hydraulic and Ecology Engineering Department, 330099 Nanchang, China \\ 2 Jiangxi Engineering Research Center of Water Engineering Safety and Resources Efficient Utilization, 330099 \\ Nanchang, China
}

\begin{abstract}
The limit state of bearing capacity of concrete and collapse state is discussed by the overload method of finite element limit analysis and finite difference software FLAC3D. Firstly, the shear strength of concrete with different strength grade is verified through the numerical limit analysis. Besides, a new method to judge the failure of concrete by calculating the concrete limit shear strain increment value is proposed. In addition, the collapse surface position and shape is simulated and the result is compared with the actual state of the destruction. The finite element limits analysis method have been tried to applied in concrete in this paper.
\end{abstract}

\section{Introduction}

The Concrete is the largest and most widely used engineering materials, which is applied in many fields such as construction, hydraulic, transportation, national defense and so on. In the architectural mechanics, concrete has properties of tensile failure, compression failure, flexural failure, but in mechanics, the destruction modes of the solid materials only have tensile failure and shear failure[1-2]. Currently, in some projects, some concrete is mainly in plastic state, such as petroleum engineering, hydraulic engineering, tunnel engineering, its bearing capacity and failure state need to be analyzed based on the elastic-plastic theory. According to the view of mechanics, concrete belongs to the geotechnical friction material, which is not only has cohesion but also friction, whose shear strength needs to be pressed by cohesion $\mathrm{c}$ and friction $\varphi$. It is very important to control the strength index of concrete. Considering that, there is no unified specification and measurement methods for $\mathrm{c}, \varphi$ of concrete and that, the cohesion and internal friction angle of soil and rock is mainly measured by direct shear test and triaxial test, so we obtain the cohesive and internal friction angle of concrete with the help of the shear test and triaxial test following the example of geotechnical material [3-6]. Due to the lack of corresponding test instrument, we have proposed to determine $\mathrm{c}, \varphi$ of concrete by combining direct shear test and uniaxial compression test.

The purpose of this article is to judge the characteristics of the ultimate bearing capacity and damage state by performing numerical simulations of concrete strength test. The overload method of finite element limit analysis and the finite difference software FLAC3D is applied in the numerical simulation. For all this, the shear strength of concrete specimens with

\footnotetext{
${ }^{a}$ Corresponding author: xiaosun@nit.edu.cn
} 
different strength grade is verified first. Then extract the ultimate shear strain increment of concrete with different strength grade and identify whether the concrete is damaged based on the limit value, providing new failure criterion for finite element limit analysis method. At last, the position and form of concrete specimen failure surface is simulated, and compare the result with the actual damage state.

In this paper, we cannot only get ultimate load and safety factor but also the position and shape of the structure failure surface by application of finite element limit analysis method. It has important academic significance and application value for the study of the force characteristics of concrete structure.

\section{Numerical simulation and experiment of concrete shear strength}

\subsection{The calculation model and parameters}

The In order to verify that compressive strength is unrelated to geometric size and shape of the model in the test above, we perform numerical simulations of 3 specimens with different size and shape based on the overload method of finite element limit analysis and finite difference software FLAC3D.

Scheme 1: model is established according to the concrete cube specimen from "specification for design of concrete structures"(GB50010-2011). The size is $150 \mathrm{~mm} \times 150 \mathrm{~mm} \times 150 \mathrm{~mm}$. Enforce vertical constraints on the bottom, and enforce vertical downward uniform distributed load on the surface, as shown in figure 1. Concrete is regarded as the ideal elastic-plastic material. The ideal elastic-plastic constitutive model and Moore - coulomb yield criterion is adopted in the calculation. Four concrete models with $\mathrm{C}_{25}, \mathrm{C} 30, \mathrm{C} 35, \mathrm{C} 40$ grade are calculated. The $c$ and $\varphi$ of concrete is obtained from the triaxial test. Extract the elastic modulus according to "specification for design of concrete structures"(GB50010-2011), as shown in table 1. The calculation model is shown in figure 2.The similarity ratio between calculation model and test model is 1:1.

Table 1. Physico-mechanical Parameters of concrete.

\begin{tabular}{|c|c|c|c|c|c|}
\hline $\begin{array}{c}\text { Surrounding } \\
\text { rock type }\end{array}$ & $\begin{array}{c}\text { Modulus of elasticity } \\
\mathrm{E} / \mathrm{GPa}\end{array}$ & $\begin{array}{c}\text { Poisson's ratio } \\
v / 1\end{array}$ & $\begin{array}{c}\text { Gravity } \\
\rho / \mathrm{kN} . \mathrm{m}-3\end{array}$ & $\begin{array}{c}\text { Cohesion } \\
\mathrm{C} / \mathrm{MPa}\end{array}$ & $\begin{array}{c}\text { Fraction angle } \\
\varphi_{/}\end{array}$ \\
\hline $\mathrm{C}_{25}$ & 28.0 & 0.2 & 2500 & 3.2 & 61.3 \\
\hline $\mathrm{C}_{30}$ & 30.0 & 0.2 & 2500 & 3.9 & 61.8 \\
\hline $\mathrm{C}_{35}$ & 31.5 & 0.2 & 2500 & 4.5 & 62.2 \\
\hline $\mathrm{C}_{40}$ & 32.5 & 0.2 & 2500 & 5.1 & 62.5 \\
\hline
\end{tabular}

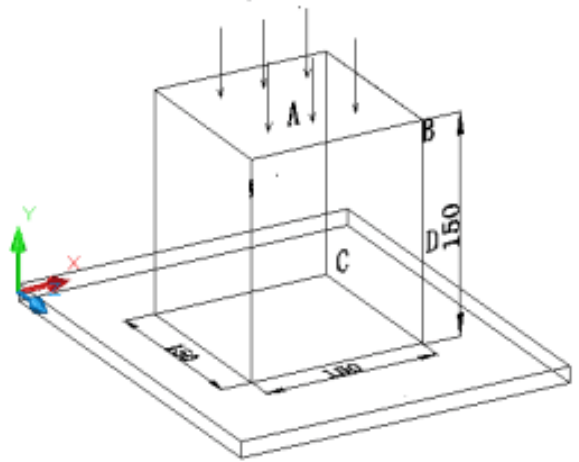

Figure 1. Geometric model.

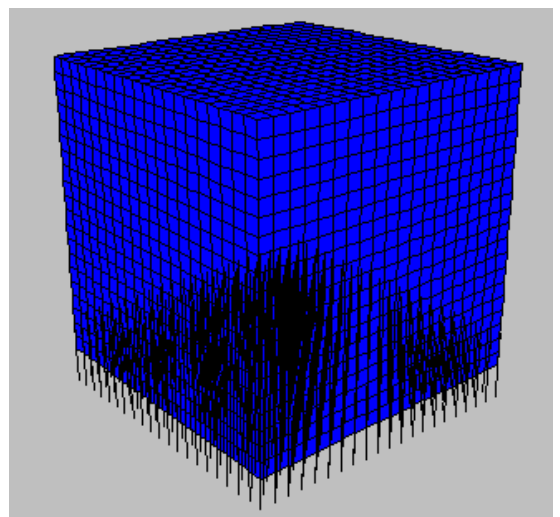

Figure 2. Calculation model. 


\subsection{Comparative analysis of the measured result and the calculated result}

Modify the load constantly during the calculation. The load when the model reaches the limit damage state is defined as the calculated compressive strength of concrete. Determine whether the model is damaged during the calculation according to the three criteria of rock and soil damage that whether the plastic zone runs through, whether the calculation converges and whether the displacement or strain mutates. During the calculation, the displacement of point A $(0.075,0.075,0.15)$ in $Z$ direction, the displacement of point $\mathrm{B}(0.15,0.00,0.15)$ in $\mathrm{Y}$ and $\mathrm{Z}$ direction, the placement of point $\mathrm{C}(0.075$, $0.00,0.075)$ in $\mathrm{Y}$ direction and the placement of point $\mathrm{C}(0.075,0.00,0.075)$ in $\mathrm{Y}$ direction is monitored. Figure 3 shows the displacement-time curve when the calculation converge, the curve is horizontal in the end. It indicates that the displacement change won't happen again and the calculation converges. Figure 4 shows the displacement-time curve when the calculation doesn't converge, it can be seen that the displacement mutate when iteration is about 2000 times, displacement shows a trend of increase, calculation won't converge. It indicates that $\mathrm{C}_{25}$ concrete specimen has been destroyed.

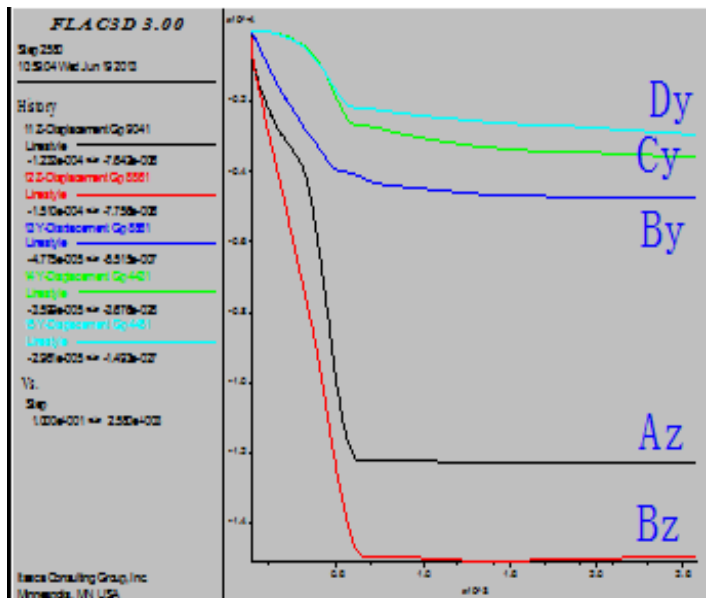

Figure 3. The displacement-time curve of key points when calculation converges the displacement-time

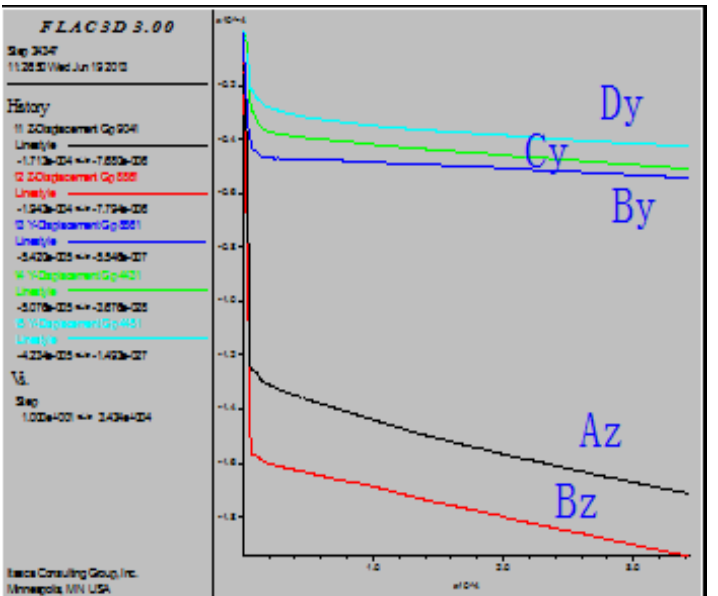

Figure 4. Curve of key points when calculation converges doesn't converge.

The comparison of measured values and calculated values of compressive strength in Scheme Iis shown in table 2.

Table 2. The comparison of measured values and calculated values of compressive strength in Scheme I.

\begin{tabular}{|c|c|c|c|}
\hline $\begin{array}{c}\text { The concrete } \\
\text { strength grade }\end{array}$ & $\begin{array}{c}\text { The calculated value of } \\
\text { compressive strength } \\
(\mathrm{MPa})\end{array}$ & $\begin{array}{c}\text { The measured value of } \\
\text { compressive strength } \\
(\mathrm{MPa})\end{array}$ & $\begin{array}{c}\text { The error between } \\
\text { calculated value and } \\
\text { measured value } \\
(\%)\end{array}$ \\
\hline $\mathrm{C}_{25}$ & 25.01 & 25.00 & 0.04 \\
\hline $\mathrm{C}_{30}$ & 31.05 & 30.00 & 3.50 \\
\hline $\mathrm{C}_{35}$ & 36.36 & 35.00 & 3.89 \\
\hline $\mathrm{C}_{40}$ & 41.68 & 40.00 & 4.20 \\
\hline
\end{tabular}

Specimens in scheme 2 are cubes with the size of $1500 \mathrm{~mm} \times 1500 \mathrm{~mm} \times 1500 \mathrm{~mm}$, other conditions are the same as scheme 1 . The calculated result is shown in table 3 . 
Table 3. The comparison of measured values and calculated values of compressive strength in Scheme II.

\begin{tabular}{|c|c|c|c|}
\hline $\begin{array}{c}\text { The concrete } \\
\text { strength grade }\end{array}$ & $\begin{array}{c}\text { The calculated value } \\
\text { of compressive } \\
\text { strength (MPa) }\end{array}$ & $\begin{array}{c}\text { The measured value } \\
\text { of compressive } \\
\text { strength (MPa) }\end{array}$ & $\begin{array}{c}\text { The error between } \\
\text { calculated value and } \\
\text { measured value } \\
(\%)\end{array}$ \\
\hline $\mathrm{C}_{25}$ & 24.98 & 25.00 & 0.08 \\
\hline $\mathrm{C}_{30}$ & 31.02 & 30.00 & 3.40 \\
\hline $\mathrm{C}_{35}$ & 36.33 & 35.00 & 3.80 \\
\hline $\mathrm{C}_{40}$ & 41.66 & 40.00 & 4.15 \\
\hline
\end{tabular}

It can be seen through the calculation above that the measured values and the calculated results of compressive strength are particularly close. The maximum error between the two is $4.20 \%$, the minimum error is $0.04 \%$. There is a small difference between the compressive strength measured values and the calculated values in different schemes with the same strength grade, it indicates that compressive strength is unrelated to the size and shape of material. It also shows that, the concrete strength parameters $C$ and $\varphi$ measured by the test are reasonable and the finite element limit analysis method which is widely applied to geotechnical engineering is also appropriate for concrete material.

\section{3 The theoretical relationship between the shear strength and compressive strength of concrete and its verification}

Due to the inconsistency development of the mechanics, in architectural mechanics which is applied to bar and artefacts, the strength of materials is usually determined by the force form of component, for example, compressive strength, tensile strength, shear strength and so on. But it is usually determined by the form of material damage in the elastic and plastic mechanics. The shear failure results from pressing in mechanics, so the material strength parameter adopts tensile strength and shear strength, it doesn't adopt compressive strength. In fact, the two are the same essentially, they just have different definition. But the shear strength of friction materials is composed of cohesion and friction. There must exist corresponding mechanical relationship between shear strength and compressive strength. For the friction materials, the following relationship can be deduced out on the basis of Mohr-Coulomb criterion:

$$
\begin{aligned}
\sigma_{1} & =\frac{1+\sin \varphi}{1-\sin \varphi} \sigma_{3}+\frac{\cos \varphi}{1-\sin \varphi} 2 c \\
\tau & =c+\sigma \tan \varphi=\frac{\sigma_{1}-\sigma_{3}}{2} \cos \varphi \\
\sigma & =\frac{\sigma_{1}+\sigma_{3}}{2}-\frac{\sigma_{1}-\sigma_{3}}{2} \sin \varphi \\
c & =\left[\frac{\sigma_{1}-\sigma_{3}}{2}-\frac{\sigma_{1}+\sigma_{3}}{2} \sin \varphi\right] \frac{1}{\cos \varphi}
\end{aligned}
$$

Where: $\sigma$-Normal stress on the shear plane.

$\tau$ - The limit of shear strength.

c, $\varphi-$ Cohesive and angle of internal friction.

$\sigma_{1}, \sigma_{3}$-The maximum and the minimum principal stress.

Concrete compressive strength test is uniaxial test, namely, $\sigma_{3}=0$, it can be obtained according to (3), (4): 


$$
\frac{\sigma \tan \varphi}{c}=\sin \varphi
$$

Thus, the value of $c$ can be obtained by direct shear test without normal pressure, then work out the value of $\varphi$. If the shear strength and compressive strength of concrete are known, of the strength can also be verified according to the above formula. Therefore, the accuracy of $c$ and $\varphi$ of concrete with different strength grade can be verified according to the above theoretical formula, as shown in table 4 . The value compressive strength and shear strength with theoretical solution and numerical solution is shown in table 4, the contribution of cohesion and friction is listed in table 8 . It can be seen from table 5 and table 6 , that friction accounts for 47 percent and cohesive accounts for 53 percent. The accuracy of the results in table 4 can be proved by formula (5). It can be seen, concrete compressive strength takes rubbing strength into consideration.

Table4. The verification of shear strength of different strength concrete.

\begin{tabular}{|c|c|c|c|c|c|}
\hline \multirow{2}{*}{$\begin{array}{c}\text { Strength grade of } \\
\text { concrete (The test } \\
\text { results) }\end{array}$} & $c$ & $\varphi$ & $\begin{array}{c}\text { Theoretical } \\
\text { solution } \sigma_{1}\end{array}$ & $\begin{array}{c}\text { Numerical } \\
\text { solution } \sigma_{1}\end{array}$ & $\begin{array}{c}\text { Eltimate load } \\
\text { Error between } \\
\text { theoretical solution and } \\
\text { numerical solution (\%) }\end{array}$ \\
\hline $\mathrm{C}_{20}$ & 2.6 & 60.09 & 20.03 & 20.03 & -0.0238 \\
\hline $\mathrm{C}_{25}$ & 3.2 & 61.3 & 25.02 & 25.01 & 0.0278 \\
\hline $\mathrm{C}_{30}$ & 3.9 & 61.8 & 31.05 & 31.05 & 0.0100 \\
\hline $\mathrm{C}_{35}$ & 4.5 & 62.2 & 36.37 & 36.36 & 0.0201 \\
\hline $\mathrm{C}_{40}$ & 5.1 & 62.5 & 41.68 & 41.68 & 0.0095 \\
\hline
\end{tabular}

Table 5. The value compressive strength and shear strength with theoretical solution and numerical solution

\begin{tabular}{|c|c|c|c|c|}
\hline \multirow{2}{*}{$\begin{array}{c}\text { Strength } \\
\text { grade of } \\
\text { concrete } \\
\text { test the }\end{array}$} & \multicolumn{2}{|c|}{ compressive strength $\sigma_{1}$} & \multicolumn{2}{c|}{ Shear strength $\tau$} \\
\cline { 2 - 5 } & $\begin{array}{c}\text { Theoretical } \\
\text { solution }\end{array}$ & $\begin{array}{c}\text { Numerical } \\
\text { solution }\end{array}$ & $\begin{array}{c}\text { Theoretical } \\
\text { solution }\end{array}$ & $\begin{array}{c}\text { Numerical } \\
\text { solution }\end{array}$ \\
\hline $\mathrm{C}_{20}$ & 20.03 & 20.03 & 4.87 & 4.87 \\
\hline $\mathrm{C}_{25}$ & 25.02 & 25.01 & 6.01 & 6.01 \\
\hline $\mathrm{C}_{30}$ & 31.05 & 31.05 & 7.34 & 7.34 \\
\hline $\mathrm{C}_{35}$ & 36.37 & 36.36 & 8.48 & 8.48 \\
\hline $\mathrm{C}_{40}$ & 41.68 & 41.68 & 9.62 & 9.62 \\
\hline
\end{tabular}

Table 6. The value cohesion and friction contributes to the shear strength of different strength concrete.

\begin{tabular}{|c|c|c|c|c|c|c|}
\hline $\begin{array}{c}\text { Strength } \\
\text { grade of } \\
\text { concrete (the } \\
\text { test results) }\end{array}$ & $\begin{array}{c}\text { Theoretical } \\
\text { solution }\end{array}$ & $\begin{array}{c}\text { Numerical } \\
\text { solution }\end{array}$ & Rate & $\begin{array}{c}\text { Theoretical } \\
\text { solution }\end{array}$ & $\begin{array}{c}\text { Numerical } \\
\text { solution }\end{array}$ & Rate \\
\hline $\mathrm{C}_{20}$ & 2.6 & 2.6 & 0.53 & 2.27 & 2.27 & 0.47 \\
\hline $\mathrm{C}_{25}$ & 3.2 & 3.2 & 0.53 & 2.81 & 2.81 & 0.47 \\
\hline
\end{tabular}




\begin{tabular}{|l|l|l|l|l|l|l|}
\hline $\mathrm{C}_{30}$ & 3.9 & 3.9 & 0.53 & 3.44 & 3.44 & 0.47 \\
\hline $\mathrm{C}_{35}$ & 4.5 & 4.5 & 0.53 & 3.98 & 3.98 & 0.47 \\
\hline $\mathrm{C}_{40}$ & 5.1 & 5.1 & 0.53 & 4.52 & 4.52 & 0.47 \\
\hline
\end{tabular}

\section{The analysis of limit shear strain increment}

The loading process of the solid materials goes through three stages, elastic, plastic and destroyed. The material will spring back to its normal shape in the elastic stage, but it won't recover in plastic stage. It can be judged from the yield criterion whether the material is elastic or plastic. The Tresca criterion or Mises criterion is applied to metal material and Mohr-Coulomb criterion is applied to geotechnical friction material. The yield state does not equal to failure state. It also can bearing load. But it will enter destroyed stage when the plasticity develops finitely. There is no clear criterion to judge whether the material is overall damaged. But we can judge whether the material is destroyed according to the global failure criterion in the limit analysis of material. As shown in figure 5, if the ideal plastic stress-strain curve is expressed by stress, it manifests as the infinite increasing of strain and the remaining constant of stress. The yield criterion and failure criteria is consistent at this point, it is difficult to distinguish damage. If the curve is expressed by strain, it is initial yielding at the beginning of yielding, the materials possess elastic limit strain $\varepsilon y$, it will not fail. But when the strain reaches to failure, it possess plastic limit strain $\varepsilon f$, the material will fail. It shows that, the limit value of shear strain exists during the failure of concrete. When the shear strain of each point on the failure surface is greater than the limit shear strain, material is known as overall failure, so it can be seen as the criterion for determining the overall failure of material. The limit shear strain is related to the strength and deformation characteristics of material, the property of different strength concrete is consistent, and then we can get the corresponding limit shear strain. And, the variation of properties of different strength concrete is minimal. Their limit shear strain is similar. It is should be indicated that, the limit shear strain of specimen will increase under the action of confining pressure due to the existing concrete fiction. But the confining pressure around the general structures does not exist or it is tiny, the change of the limit shear strain can be ignored.

The paper will give the limit strain of different strength concrete through the finite element limit analysis. Shear strain is presented by the increment in FLAC. The shear strain increment is similar to the shear strain in the mall deformation, so the shear strain increment is the cumulative shear strain increment, not the increment of the current step. This paper utilizes the software FLAC, so the limit shear strain given means the cumulative shear strain increment.

In the above calculation of concrete specimens with three kinds of size and shape, the cohesion $c$, internal friction Angle $\varphi$, bulk modulus $\mathrm{K}$ and shear modulus $\mathrm{G}$ of different strength concrete differs from each other. The calculation made the model to the limit equilibrium state by overload of the finite element analysis method, now we can get limit load and limit shear strain increment of the model. The shear strain increment will reach the value that can make the model destroyed by increasing the load slightly and repeating the calculation. The shear strain increment when the model failure is greater than the value of the limit equilibrium state. The results are shown in table 7 , table 8 .

Table 7. The shear strain increment contrast of Scheme I.

\begin{tabular}{|c|c|c|c|}
\hline \multirow{2}{*}{$\begin{array}{c}\text { The concrete } \\
\text { strength grade }\end{array}$} & \multirow{2}{*}{$\begin{array}{c}\text { The calculated } \\
\text { compressive } \\
\text { strength (MPa) }\end{array}$} & \multicolumn{2}{|c|}{$\begin{array}{c}\text { The minimum range of shear strain } \\
\text { increment }(\%)\end{array}$} \\
\cline { 3 - 4 } & & Limit state & Damaged \\
\hline $\mathrm{C}_{25}$ & 25.01 & $0.980----1.000$ & $1.063----1.200$ \\
\hline $\mathrm{C}_{30}$ & 31.05 & $1.058----1.100$ & $1.269----1.613$ \\
\hline $\mathrm{C}_{35}$ & 36.36 & $1.306----1.350$ & $1.363---1.400$ \\
\hline $\mathrm{C}_{40}$ & 41.68 & $1.419----1.500$ & $1.525---1.513$ \\
\hline
\end{tabular}


Table 8. The shear strain increment contrast of Scheme II.

\begin{tabular}{|c|c|c|c|}
\hline \multirow{2}{*}{$\begin{array}{c}\text { The concrete } \\
\text { strength grade }\end{array}$} & \multirow{2}{*}{$\begin{array}{c}\text { The calculated } \\
\text { compressive } \\
\text { strength }(\mathrm{MPa})\end{array}$} & \multicolumn{2}{|c|}{$\begin{array}{c}\text { The minimum range of shear strain } \\
\text { increment }(\%)\end{array}$} \\
\cline { 3 - 4 } & 24.98 & $0.972----1.000$ & Damaged \\
\hline $\mathrm{C}_{25}$ & 31.02 & $1.208----1.250$ & $1.066----1.100$ \\
\hline $\mathrm{C}_{30}$ & 36.33 & $1.284---1.300$ & $1.381---1.350$ \\
\hline $\mathrm{C}_{35}$ & 41.66 & $1.454----1.600$ & 1.600 \\
\hline $\mathrm{C}_{40}$ & & & \\
\hline
\end{tabular}

The result shows that, the limit shear strain increment of concrete with the same strength grade in three schemes is similar to each other. As shown in table9, The value in scheme 1 is $1.000 \%-1.063 \%$, the value in scheme 2 is $1.000 \%$ - $1.066 \%$. The maximum range is $0.950 \%$ - $1.109 \%$, it can be regarded as the limit shear strain increment of C25 concrete. Similarly, the limit shear strain increment can be determined as $1.100 \%$ - $1.301 \%$ or $\mathrm{C} 30,1.300 \%$ - $1.426 \%$ for $\mathrm{C} 35$ and $1.500 \%$ - $1.614 \%$ o for $\mathrm{C} 40$. The limit shear strain increment of different strength concrete will increase along with the increasing of strength, but it change slightly.

Table 9. Setting Word's margins.

\begin{tabular}{|c|c|c|c|c|}
\hline value range & $\mathrm{C} 25$ & $\mathrm{C} 30$ & $\mathrm{C} 35$ & $\mathrm{C} 40$ \\
\hline Scheme 1 & $1.000-1.063$ & $1.100-1.269$ & $1.350-1.363$ & $1.500-1.525$ \\
\hline Scheme 2 & $1.000-1.066$ & $1.250-1.301$ & $1.300-1.381$ & $1.600-1.614$ \\
\hline $\begin{array}{c}\text { The range of limit } \\
\text { shear strain } \\
\text { increment }\end{array}$ & $0.950-1.109$ & $1.100-1.301$ & $1.300-1.426$ & $1.500-1.614$ \\
\hline
\end{tabular}

\section{The failure surface comparison of test and numerical simulation}

The failure surface shape of $\mathrm{C}_{25}$ grade concrete specimen is shown in figure 6 , the specimen appears as $\mathrm{X}$ truncated cone after the destruction. In order to find out the accurate failure surface position of concrete, first calculate the range of the $\mathrm{C}_{25}$ concrete limit shear strain increment, which is 0.950 $1.109 \%$, so $1.000 \%$ can be regarded as the value of the limit shear strain increment. Then judge the destroyed cell in the model according that. This process can be realized in the post-processing by programming with FLAC's native FISH language.

Clearly, intercept half of the model by vertical plane. It is the shear strain increment cloud after the above processing, as shown in figure 6 . The shear strain increment on the failure surface ranges from $1.000 \%$ to $1.500 \%$. The failure surface appears to be $\mathrm{X}$ from the figure. The shear strain increment shows a trend of increase from the failure surface to the surface of the specimen, and it indicates that the area outside the failure surface is entirely destroyed. The shear strain increment shows a trend of decrease from the failure surface to the inside of the specimen and it indicates that the area inside the failure surface is not destroyed. The deepest edge of the destroyed part in the numerical simulation is $10.19 \mathrm{~cm}$ from the upper surface and $4.67 \mathrm{~cm}$ from the right surface. In the test, it is $10.74 \mathrm{~cm}$ from the upper surface and $3.93 \mathrm{~cm}$ from the right surface. The form and damage range of the failure surface of the calculation is similar to the result of the test. It shows that, the form and position of the failure surface can be obtained by the application of the finite element limit analysis method. 


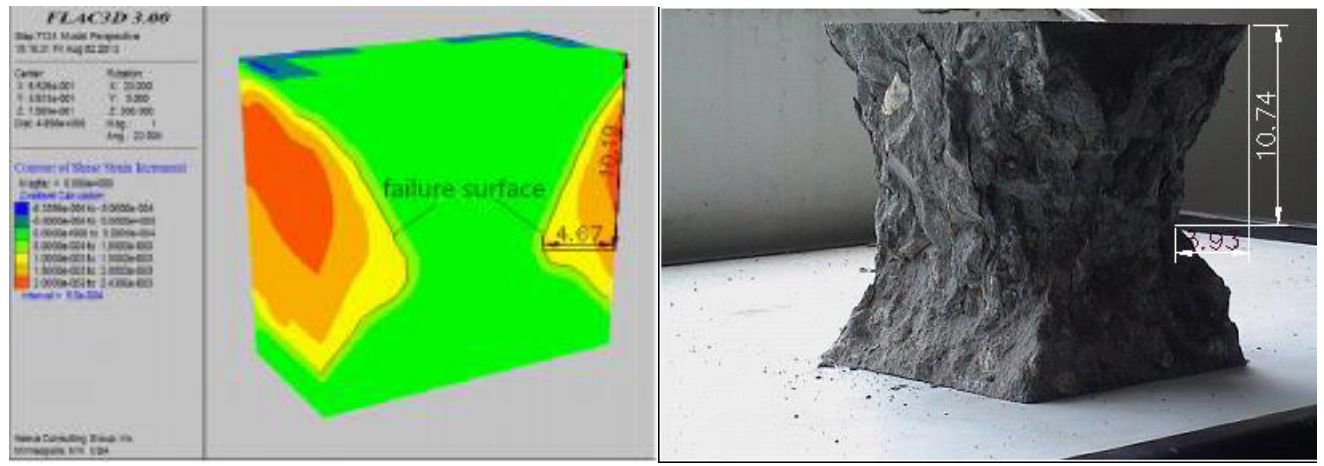

Figure 5.Failure surface of numerical simulation.

Figure 6. Failure surface of concrete test.

\section{Conclusions}

This article is attempted to obtain the ultimate load and safety factor of the concrete material by the application of finite element limit analysis method. Hope to be able to cause the attention of academia. The conclusions were obtained as follow:

(1) The calculated value of the concrete comprehensive strength is consistent with the measured value, the maximum error is $4.20 \%$ and the minimum error is $0.04 \%$. It shows that the concrete strength parameters $c$ and $\varphi$ determined by the test is reasonable.

(2) The shear strain increment of different strength concrete in the limit failure state is calculated. The interval value of the limit shear strain increment is given. It can be regarded as the criterion for the overall damage of the concrete. Provide a new criterion to determine whether the concrete is broken.

(3) The form and damage range of the failure surface of the calculation is similar to the result of the test. It shows that, the failure surface can be obtained by the application of the finite element limit analysis method.

\section{Acknowledgement}

This work was supported by grant of No.GJJ151111 from Youth Project of the Education Department of Jiangxi Province in China.

\section{References}

1. ZHENG Ying-ren, Kong Liang,Geotechnical Plastic Mechanics, Beijing: China Building industry Press, (2010)

2. ZHENG Ying-ren, ZHU He-hua, FANG Zheng-chang, The stability analysis and design theory of surrounding rock of underground engineering, Beijing: China Communications Press, (2012)

3. National Standard of the People' s Republic of China, Standard for evaluation of concrete compressive strength(GB/T50107-2010),Beijing: China Architecture \& Building Press, (2010)

4. National Standard of the People' s Republic of China,Standard for test method of mechanical properties on ordinary concrete(GB/T50081-2002),Beijing: China Architecture \& Building Press, (2003)

5. National Standard of the People' $s$ Republic of China,Code for design of concrete structures(GB/T50010-2010),Beijing: China Architecture \& Building Press, (2011)

6. ZHANG Qi, GUO Zhen-hai. Research of shear strength and shear deformation of concrete, Journal of Building Structures, 13(5),pp: 17 - 24,(1992) 